\title{
Consumo e Digestibilidade Aparente Total e Parcial de Rações com Cana-de-açúcar, Casca e Raspa de Mandioca Ensiladas com Polpa Cítrica ${ }^{1}$
}

\author{
Djalma de Freitas ${ }^{2}$, Telma Teresinha Berchielli ${ }^{3}$, Roselene Nunes da Silveira ${ }^{4}$, \\ João Paulo Guimarães Soares ${ }^{2}$, Alexandre Vaz Pires ${ }^{5}$, Pedro de Andrade ${ }^{6}$
}

\begin{abstract}
RESUMO - O objetivo deste estudo foi avaliar o consumo e a digestibilidade aparente total (DAT) e parcial dos nutrientes das silagens de cana-de-açúcar ( $\mathrm{SCnPc}$ ), de raspa (SRpPc) e de casca de mandioca ( $\mathrm{SCcPc}$ ) ensiladas com polpa cítrica peletizada (PCP). A dieta basal foi constituída de silagem de milho com farelo de soja, participando com $60 \%$ da matéria seca (MS) dos tratamentos com SRpPc e SCcPc. Foram utilizados novilhos mestiços, fistulados no rúmen e duodeno, num delineamento experimental em quadrado latino (4x4). A determinação do coeficiente de digestibilidade total e parcial dos nutrientes, a produção fecal e o fluxo duodenal de MS foram estimados a partir da fibra detergente ácido indigestível. Os consumos de MS e proteína bruta (PB) (\% PV) foram superiores para a SMi $(2,47$ e $0,33), \operatorname{SCcPc}(2,12$ e 0,30$)$ e SRpPc $(1,88$ e 0,27$)$ em relação à $\operatorname{SCnPc}(1,38$ e 0,19$)$, respectivamente. As DAT da matéria seca $(65,0 \%)$, matéria orgânica $(66,9 \%)$ e energia bruta $(64,3 \%)$ para a SRpPc foram superiores em relação às demais dietas, menos para a FDN (39,4\%). Os coeficientes de digestibilidade ruminal (CDR) e intestinal (CDI) da MS, MO e PB não apresentaram diferenças significativas entre as dietas, somente o CDR da FDN (\% ingerido) apresentou valores superiores para SMi $(43,5), \operatorname{SRpPc}(39,3)$ e SCnPc $(37,0)$, sobre a $\operatorname{SCcPc}(20,0)$. A utilização da silagem de raspa de mandioca adicionada da PCP mostrou-se uma alternativa de boa qualidade na alimentação de bovinos.
\end{abstract}

Palavras-chave: fibra em detergente ácido indigestível, ingestão, partição da digestão, resíduos da mandioca, valor nutritivo

\section{Intake and Total and Partial Apparent Digestibility of Rations with Sugar Cane, Cassava Hull and Cassava Root Ensiled with Citrus Pulp}

\begin{abstract}
The goal of this study was to evaluate the intake of nutrients and the total and partial apparent digestibility of sugar cane + citrus pulp $(\mathrm{ScSCp})$, cassava hulls + citrus pulp $(\mathrm{ChSCp})$ and cassava root + citrus pulp $(\mathrm{CrSCp})$ silages. The basal diet with corn silage (CS) and soybean meal composed $60 \%$ of the total dry matter of ChSCp and CrSCp treatments. Four castrated crossbred (HxZ) steers were, canulated in the rumen and in the duodenum and confined according to $4 \times 4$ Latin Square design. For total and partial digestibility of nutrients determination, the dry matter (DM) fecal output and duodenal flow, were estimated by neutral detergent fiber. The DM and crude protein (CP) intake (\%LW) of CS (2.47 and 0.33), ChSCp (2.12 and 0.30) and CrSCp (1.88 and 0.27) were higher than ScSCp (1.38 and 0.19). The dry matter (65.0\%), organic matter (66.9\%), and the gross energy (64.3\%) total apparent digestibilities were higher than the other diets, with the exception for NDF (39.4\%). The DM, OM and CP ruminal (RDC) and intestinal (IDC) digestibility coefficients, as percentage of intake, did not show significant differences among the diets. The RDC of the NDF to diets: CS (43.4\%), the CrSCp (39.3\%), and the ScSCp (37.0\%) were higher than ChSCp (20.0\%). The cassava meal + citrus pulp silage utilization showed to be a good alternative for bovine feeding.
\end{abstract}

Key Words: cassava residue, digestion partition, indigestible acid detergent fiber, intake, nutritional value

\section{Introdução}

Um suprimento adequado de energia e proteína nos alimentos traz como conseqüência uma melhor utilização dos nutrientes para os processos produtivos e reprodutivos dos animais. A deficiência energética afeta negativamente os índices produtivos e reprodutivos dos animais, diminui o crescimento, o ganho em peso, a produção leiteira, o intervalo de partos, a idade da primeira cria, entre outros, comprometendo a rentabilidade do sistema produtivo.

A eficiência da energia para produção de carne aumenta significativamente à medida que o alimento apresenta maiores níveis de energia, tornando-se indispensável o uso de suplementos energéticos. No entanto, o preço desses suplementos tem sido o fator

\footnotetext{
${ }^{1}$ Parte da dissertação de mestrado do primeiro autor da FCAVJ-UNESP.

${ }^{2}$ Alunos de Doutorado da FCAVJ/Unesp - Bolsistas FAPESP. E.mail: djalma@fcav.unesp.br

3 Professora do Depto de Zootecnia da FCAVJ/Unesp. Pesquisadora do CNPq. E.mail: ttberchi@fcav.unesp.br

${ }^{4}$ Aluna de Doutorado da FCAVJ/Unesp - Bolsista CNPq. E.mail: silveira@fcav.unesp.br

5 Professor do Depto de Zootecnia da ESALQ/USP.

${ }^{6}$ Professor Aposentado do Depto de Zootecnia da FCAVJ/UNESP.
} 
que mais onera os custos na pecuária bovina no país. Isso tem aumentado o interesse de técnicos e empresários rurais sobre fontes alternativas de alimentos para os animais. Nesse contexto, insere-se a utilização de resíduos agrícolas e/ou subprodutos da agroindústria que, segundo Burgi (2000), se distinguem pela existência ou não de um mercado definido para sua comercialização.

Alguns subprodutos apresentam extensa pesquisa sobre sua utilização, como o caso do farelo de soja e da polpa cítrica peletizada. Diversos resíduos, entretanto, ainda carecem de estudos para que possam ser empregados em larga escala e tenham minimizado seu efeito poluente. Dentre esses, destacam-se resíduos da indústria da mandioca, como a casca, constituindo-se de pontas, cascas e películas, representando $4,5 \%$ do total de mandioca processada, com teor de umidade de $88 \%$ (Cereda, 1996).

Durante o processo de lavagem, ao qual é submetida a massa de mandioca para obtenção do polvilho, obtém-se outro resíduo denominado raspa de mandioca e que também apresenta alta umidade. Os baixos teores de MS verificados nesses resíduos apresentam problemas quanto ao seu transporte e armazenamento, necessitando de algum tipo de processamento que viabilize sua utilização (Burgi, 2000).

A ensilagem pode ser uma alternativa para os resíduos apresentados, porém há necessidade de ajustar o seu teor de matéria seca (MS), adicionando outro alimento que apresente teor mais elevado de MS. A viabilidade econômica do processo, contudo, está associada ao custo final por tonelada de nutriente ensilada.

A polpa cítrica peletizada (PCP) apresenta-se como alternativa, especialmente nos últimos anos, devido ao aumento de produtividade dos pomares e à suspensão das exportações. Então gouve excedente dessa polpa no mercado interno, chegando a ser comercializada pelo valor do transporte (Sorbara et al., 2000).

Em função da sua qualidade nutricional já conhecida, e devido sua ampla utilização na nutrição de ruminantes (Henrique et al., 1998), buscaram-se formas alternativas de armazenamento, dentre as quais a adição de água e posterior ensilagem (Ribeiro, 1998).

Como as indústrias que processam a laranja estão concentradas no Estado de São Paulo, outra alternativa de armazenamento da PCP é sua ensilagem com a cana-de-açúcar, que ocorre em abundância na região e tem teor de matéria seca de $26 \%$ a $28 \%$, permitindo adição de aproximadamente $35 \%$ da matéria seca da silagem como PCP. A cana, ao ser ensilada, permite otimizar o uso da mão-de-obra, que se concentra no momento da ensilagem. Favorece também a rebrota em função do corte rápido e uniforme, ficando a silagem disponível para utilização no período mais conveniente (Valvasori et al., 1997).

Assim, a avaliação nutricional desses alimentos torna-se necessária para a caracterização do seu potencial e utilização na composição de dietas de ruminantes, que envolvem estudos de digestibilidade, que podem ser subdivididos conforme o local de digestão no trato digestório. Dessa forma, o objetivo do presente estudo foi avaliar o consumo e a digestibilidade aparente total e parcial dos nutrientes contidos em dietas com silagens de cana-de-açúcar, raspa e casca de mandioca ensiladas com polpa cítrica peletizada por novilhos.

\section{Material e Métodos}

Foram utilizadas dietas constituídas de silagem de raspa e de casca de mandioca e cana-de-açúcar, adicionadas de polpa cítrica peletizada (PCP), como aditivo, afim de ajustar a matéria seca (MS) das mesmas. A dieta constituída com silagem de milho e farelo de soja foi usada como volumoso para as dietas com raspa e casca de mandioca com PCP. As proporções de $\mathrm{PCP}$ adicionadas às silagens de raspa $(46,6 \%)$ e casca de mandioca $(36,3 \%)$, assim como a silagem de cana-de-açúcar $(44,6 \%)$, foram usadas com o objetivo de alcançar os teores de MS na silagem ao redor de $40 \%, 35 \%$ e $40 \%$, respectivamente. No entanto, valores inferiores aos esperados foram obtidos, possivelmente associados à vedação deficiente dos silos experimentais (Tabela 1).

As dietas foram calculadas considerando-se o potencial de crescimento microbiano, como duas vezes a mantença e, para ajustar o potencial de nitrogênio degradável utilizou-se o farelo de soja e a uréia conforme o AFRC (1995). A composição química e percentual dos ingredientes das dietas (\%MS) encontram-se nas Tabelas 1 e 2.

Foi usada uma dieta basal que continha silagem de milho e farelo de soja. Dessa forma possibilitou o cálculo da digestibilidade pelo processo indireto (Lucci, 1997) da silagem de raspa e da silagem de casca de mandioca com PCP, utilizadas como alimentos 
Tabela 1 - Composição química e percentual dos ingredientes nas dietas (\%MS)

Table 1 - Chemical and percent composition of ingredient in diets (\%DM)

\begin{tabular}{|c|c|c|c|c|c|}
\hline $\begin{array}{l}\text { Ingredientes } \\
\text { Ingredients }\end{array}$ & $\begin{array}{l}\text { MS } \\
D M\end{array}$ & $\begin{array}{l}\mathrm{MO} \\
O M\end{array}$ & $\begin{array}{l}\mathrm{PB} \\
C P\end{array}$ & $\begin{array}{l}\mathrm{CHO}^{1} \\
\mathrm{COH}^{1}\end{array}$ & $\begin{array}{l}\text { FDN } \\
N D F\end{array}$ \\
\hline $\begin{array}{l}\text { Silagem de milho } \\
\text { Corn silage }\end{array}$ & 31,07 & 95,02 & 8,51 & 83,84 & 50,61 \\
\hline $\begin{array}{l}\text { Sil. Raspa }+ \text { polpa cítrica } \\
\text { Cassava root silage }+ \text { citrus pulp }\end{array}$ & 31,12 & 93,84 & 5,87 & 86,72 & 27,14 \\
\hline $\begin{array}{l}\text { Sil. Casca + polpa cítrica } \\
\text { Cassava hulls silage + citrus pulp }\end{array}$ & 30,92 & 86,08 & 6,24 & 78,46 & 50,25 \\
\hline $\begin{array}{l}\text { Sil. Cana }+ \text { polpa cítrica } \\
\text { Sugar cane silage }+ \text { citrus pulp }\end{array}$ & 29,10 & 94,97 & 5,80 & 87,71 & 55,15 \\
\hline $\begin{array}{l}\text { Farelo de soja } \\
\text { Soybean meal }\end{array}$ & 90,54 & 93,64 & 48,23 & 44,15 & 18,55 \\
\hline $\begin{array}{l}\text { Uréia } \\
\text { Urea }\end{array}$ & 99,00 & - & $275,00^{*}$ & - & - \\
\hline
\end{tabular}

\begin{tabular}{|c|c|c|c|c|}
\hline \multirow{3}{*}{$\begin{array}{l}\text { Ingredientes }(\% \mathrm{MS}) \\
\text { Ingredients }(\% D M)\end{array}$} & \multicolumn{4}{|c|}{$\begin{array}{c}\text { Tratamentos }(\% \mathrm{MS}) \\
\text { Treatments }(\% D M)\end{array}$} \\
\hline & SMi & SRpPc & $\mathrm{SCcPc}$ & $\mathrm{SCnPc}$ \\
\hline & $C S$ & $C r S C p$ & $C h S C p$ & $S C S C p$ \\
\hline Silagem de milho (SMi) & 87,10 & 51,49 & 51,52 & - \\
\hline Corn silage (CS) & & & & \\
\hline Sil. raspa + polpa cítrica $(\mathrm{SRpPc})$ & - & 39,36 & - & - \\
\hline Cassava root silage + citrus pulp $(\mathrm{CrSCp})$ & & & & \\
\hline $\begin{array}{l}\text { Sil. Casca+polpa cítrica }(\mathrm{SCcPc}) \\
\text { Cassava hulls silage }+ \text { citrus pulp }(\text { CHSCp })\end{array}$ & - & - & 39,39 & - \\
\hline $\begin{array}{l}\text { Sil. Cana+polpa cítrica }(\mathrm{SCnPc}) \\
\text { Sugar cane silage+citrus pulp (SCSCp) }\end{array}$ & - & - & - & 96,92 \\
\hline Farelo de soja & 12,90 & 7,64 & 7,65 & - \\
\hline $\begin{array}{l}\text { Soybean meal } \\
\text { Uréia } \\
\text { Urea }\end{array}$ & - & 1,51 & 1,44 & 3,08 \\
\hline
\end{tabular}

* = equivalente protéico.

${ }^{1} \mathrm{CHO}=100-(\% \mathrm{~PB}+\% \mathrm{EE}+\%$ cinzas $)$ Sniffen et al. (1992)

$\mathrm{MS}=$ matéria seca; $\mathrm{MO}=$ matéria orgânica; $\mathrm{PB}=$ proteína bruta; $\mathrm{CHO}=$ carboidratos totais; FDN = fibra detergente neutro

* $=$ protein equivalent.

${ }^{1} \mathrm{COH}=100-(\% \mathrm{CP}+\% \mathrm{EE}+\%$ ash $)$ Sniffen et al. (1992) .

$D M=$ dry matter; $\mathrm{OM}=$ organic matter, $\mathrm{CP}=$ crude protein; $\mathrm{COH}=$ total carbohydrates; $N D F=$ neutral detergent fiber

energéticos. A dieta basal representou aproximadamente $60 \%$ das dietas que contêm silagem de raspa e casca de mandioca com PCP.

O fornecimento das dietas foi realizado diariamente às 7 e 13 horas, juntamente com $70 \mathrm{~g}$ de mistura mineral por animal (para cada $\mathrm{kg}, \mathrm{Ca}-60 \mathrm{~g}$; $\mathrm{P}$ - 45g; S - 4,12g; Na - 152,0g; Co - 38,90mg; Cu - 1.050mg; Fe - 1.300mg; I - 50,25mg; Mn $1.000 \mathrm{mg}$; Se $-9 \mathrm{mg}$ e $\mathrm{Zn}-2.520 \mathrm{mg}$. O consumo foi ajustado para permitir sobras da ordem de $10 \%$ da MS fornecida.

Os valores de energia digestível (ED) foram obtidos a partir dos coeficientes de digestibilidade da energia bruta (EB). Os valores de energia metabolizável (EM), energia líquida de mantença
(Elm) e energia líquida de ganho (Elg) foram calculados conforme Sniffen et al. (1992), sendo:

$$
\mathrm{EM}=0,82 \mathrm{ED}
$$

$$
\begin{aligned}
& \mathrm{Elm}=-1,12+1,37 \mathrm{EM}-0,138 \mathrm{EM}^{2}+0,0105 \mathrm{EM}^{3} \\
& \mathrm{Elg}=-1,65+1,42 \mathrm{EM}-0,174 \mathrm{EM}^{2}+0,0122 \mathrm{EM}^{3}
\end{aligned}
$$

O experimento foi dividido em quatro períodos de 19 dias, sendo 11 dias de adaptação à dieta e oito dias de coleta de amostras, totalizando 76 dias. Os animais foram mantidos em baias individuais durante onze dias e, a seguir, alojados em gaiolas para estudo de metabolismo, providas de bandeja coletora de fezes, com piso ripado de madeira e cochos apropriados para o fornecimento de alimento e água.

As amostras de fezes foram coletadas diariamente às $7 \mathrm{~h}$, na bandeja coletora, após homogeneização 
Tabela 2 - Composição química das dietas (\%MS)

Table 2 - Chemical composition of the diets (\%DM)

\begin{tabular}{|c|c|c|c|c|c|c|}
\hline $\begin{array}{l}\text { Tratamentos } \\
\text { Treatments }\end{array}$ & $\begin{array}{l}\text { MS } \\
D M\end{array}$ & $\begin{array}{l}\mathrm{MO} \\
O M\end{array}$ & $\begin{array}{l}\mathrm{PB} \\
C P\end{array}$ & $\begin{array}{l}\mathrm{CHO}^{1} \\
\mathrm{COH}^{1}\end{array}$ & $\begin{array}{l}\text { FDN } \\
N D F\end{array}$ & $\begin{array}{l}\mathrm{NDT}^{1} \\
T D N^{1}\end{array}$ \\
\hline $\begin{array}{l}\text { Silagem de milho }(\mathrm{SMi}) \\
\text { Corn silage }(C S)\end{array}$ & 38,83 & 94,90 & 13,63 & 78,71 & 46,48 & 57,73 \\
\hline $\begin{array}{l}\text { Sil. raspa }+ \text { polpa cítrica }(\mathrm{SRpPc}) \\
\text { Cassava root silage }+ \text { citrus pulp }(C r S C p)\end{array}$ & 36,66 & 93,12 & 14,73 & 80,55 & 38,11 & 68,35 \\
\hline $\begin{array}{l}\text { Sil. casca + polpa cítrica }(\mathrm{SCcPc}) \\
\text { Cassava hulls silage }+ \text { citrus pulp }(C h S C p)\end{array}$ & 36,49 & 90,02 & 14,28 & 77,62 & 47,33 & 50,05 \\
\hline $\begin{array}{l}\text { Sil. cana + polpa cítrica }(\mathrm{SCnPc}) \\
\text { Sugar cane silage + citrus pulp }(S c S C p)\end{array}$ & 31,25 & 92,16 & 13,78 & 85,14 & 53,51 & 59,83 \\
\hline
\end{tabular}

das mesmas, em quantidade de aproximadamente $500 \mathrm{~g}$, sendo então acondicionadas em sacos plásticos, devidamente identificadas e congeladas para, ao final do período de coleta, formarem a amostra composta, representativa do mesmo.

Foi realizada coleta de conteúdo duodenal, via cânula, em quantidade de $500 \mathrm{~mL}$, durante um período de quatro dias, duas vezes ao dia, conforme o esquema descrito a seguir: $1^{\circ} \mathrm{dia}-8 \mathrm{~h}$ e $16 \mathrm{~h} ; 2^{\circ} \mathrm{dia}-$ $10 \mathrm{~h}$ e $18 \mathrm{~h} ; 3^{\circ} \mathrm{dia}-12 \mathrm{~h}$ e $20 \mathrm{~h}$ e $4^{\circ}$ dia às 14 horas. Após cada coleta as amostras foram imediatamente congeladas para posterior determinação da $\mathrm{MS}$, a $65^{\circ} \mathrm{C}$, sendo, a seguir, reunidas em uma amostra composta.

Para determinar as digestibilidades e o fluxo duodenal de MS, utilizou-se como indicador interno a fibra em detergente ácido indigestível (FDAI), obtida pelo método in vitro, após 144 horas de incubação (Berchielli et al., 2000).

As amostras de alimentos, sobras, fezes e conteúdo duodenal foram moídas e submetidas à análise de matéria seca (MS), matéria orgânica (MO), proteína bruta (PB), extrato etéreo (EE), matéria mineral (MM), segundo procedimentos descritos pela AOAC (1990), e fibra em detergente neutro (FDN), conforme Jeraci et al. (1988).

O delineamento utilizado foi em quadrado latino (4x4), para comparar a ingestão e o local de digestão dos nutrientes. A análise de variância e a comparação de médias pelo teste de Tukey, em nível de 5\% de significância, foram obtidas pelo PROC GLM do SAS (1985).

\section{Resultados e Discussão}

Os dados referentes ao consumo de MS, MO, $\mathrm{PB}, \mathrm{FDN}$ e NDT das dietas, expressos em \% do peso vivo $(\% \mathrm{PV})$ e $\mathrm{g} / \mathrm{kg} \mathrm{PV}^{0,75}$, encontram-se apresentados na Tabela 3 . O consumo de MS foi maior $(\mathrm{P}<0,05)$ para a silagem de milho $(\mathrm{SMi})$, silagem de casca de mandioca ( $\mathrm{SCcPc}$ ) e silagem de raspa de mandioca ( $\mathrm{SRpPc}$ ), apresentando os valores de 2,$47 ; 2,12$ e 1,88\% PV, respectivamente, em relação à silagem de cana-de-açúcar $(\mathrm{SCnPc})$. No entanto, a SRpPc não diferiu da $\operatorname{SCnPc}(1,38$ $\% \mathrm{PV})$, que foi inferior $(\mathrm{P}<0,05)$ às demais ( $\mathrm{SMi} \mathrm{e}$ $\mathrm{SRpPc})$, mesmo quando expresso em $\mathrm{g} / \mathrm{kg} \mathrm{PV}^{0,75}$.

A baixa ingestão de MS da SCnPc pode ser atribuída à predominância de fermentação alcoólica, decorrente da rápida proliferação de leveduras com produção de etanol e gás carbônico (Valvasori et al., 1997), verificada durante o período experimental pelo pronunciado odor de álcool presente e também pelo alto teor de FDN dessa dieta (Tabela 2). Todavia, o valor observado $\left(55,97 \mathrm{~g} / \mathrm{kg} \mathrm{PV}^{0,75}\right)$ foi superior ao obtido para a cana-de-açúcar in natura, fornecida a novilhos mestiços, adicionada com 4 níveis de uréia $(0 ; 0,5 ; 1,0$ e $1,5 \%$ na matéria natural), verificados por Oliveira (1990) e citados por Rodriguez (1995), que observou consumo de MS de 35,0; 48,4; 41,7 e $43,3 \mathrm{~g} / \mathrm{kg} \mathrm{PV}^{0,75}$, respectivamente, para os níveis de uréia.

Para a SCcPc verificou-se valor de $2,12 \% \mathrm{PV}$, lembrando que essa dieta é a que possui menor 
Tabela 3 - Consumos médios diários de matéria seca (MS), de matéria orgânica (MO), de proteína bruta (PB), de fibra detergente neutro (FDN) e de nutrientes digestíveis totais (NDT).

Table 3 - Intake of dry matter (DM), of organic matter (OM), of crude protein (CP), of neutral detergent fiber (NDF) and of total digestible nutrients (TDN)

\begin{tabular}{|c|c|c|c|c|c|c|}
\hline \multirow{3}{*}{$\begin{array}{l}\text { Parâmetro } \\
\text { Parameter }\end{array}$} & \multicolumn{4}{|c|}{$\begin{array}{c}\text { Ração } \\
\text { Diets }\end{array}$} & \multirow{3}{*}{$\mathrm{CV}$} & \multirow{3}{*}{$\begin{array}{l}\text { DMS } \\
M S D\end{array}$} \\
\hline & SMi & SRpPc & $\mathrm{SCcPc}$ & $\mathrm{SCnPc}$ & & \\
\hline & $C S$ & $C r S C p$ & $C h S C p$ & $S c S C p$ & & \\
\hline \multicolumn{7}{|c|}{$\begin{array}{c}\text { Consumo de MS } \\
\text { DM intake }\end{array}$} \\
\hline$\% \mathrm{PV}(\% B W)$ & $2,47^{\mathrm{A}}$ & $1,88^{\mathrm{AB}}$ & $2,12^{\mathrm{A}}$ & $1,38^{\mathrm{B}}$ & 13,02 & 0,62 \\
\hline $\mathrm{g} / \mathrm{kg}^{0,75}$ & $100,10^{\mathrm{A}}$ & $76,31^{\mathrm{AB}}$ & $86,31^{\mathrm{A}}$ & $55,97^{\mathrm{B}}$ & 12,77 & 24,91 \\
\hline \multicolumn{7}{|c|}{ Consumo de $\mathrm{MO}$} \\
\hline$\% \mathrm{PV}(\% \mathrm{~B} W)$ & $2,34^{\mathrm{A}}$ & $1,75^{\mathrm{BC}}$ & $1,91^{\mathrm{AB}}$ & $1,28^{\mathrm{C}}$ & 12,70 & 0,56 \\
\hline $\mathrm{g} / \mathrm{kg}^{0,75}$ & $94,97^{\mathrm{A}}$ & $70,94^{\mathrm{BC}}$ & $77,69^{\mathrm{AB}}$ & $51,52^{\mathrm{C}}$ & 12,40 & 22,39 \\
\hline \multicolumn{7}{|c|}{$\begin{array}{l}\text { Consumo de } \mathrm{PB} \\
\text { CP intake }\end{array}$} \\
\hline$\% \mathrm{PV}(\% B W)$ & $0,33^{\mathrm{A}}$ & $0,27^{\mathrm{AB}}$ & $0,30^{\mathrm{A}}$ & $0,19^{\mathrm{B}}$ & 13,50 & 0,09 \\
\hline $\mathrm{g} / \mathrm{kg}^{0,75}$ & $13,61^{\mathrm{A}}$ & $11,06^{\mathrm{AB}}$ & $12,50^{\mathrm{A}}$ & $7,89^{\mathrm{B}}$ & 12,66 & 3,49 \\
\hline \multicolumn{6}{|c|}{ Consumo de FDN } & \\
\hline$\% \mathrm{PV}(\% B W)$ & $1,14^{\mathrm{A}}$ & $0,73^{\mathrm{B}}$ & $1,00^{\mathrm{AB}}$ & $0,71^{\mathrm{B}}$ & 15,57 & 0,34 \\
\hline $\mathrm{g} / \mathrm{kg}^{0,75}$ & $46,46^{\mathrm{A}}$ & $29,15^{\mathrm{B}}$ & $40,79^{\mathrm{AB}}$ & $29,79^{\mathrm{B}}$ & 15,43 & 13,80 \\
\hline \multicolumn{7}{|c|}{$\begin{array}{l}\text { Consumo de NDT } \\
\text { TDN intake }\end{array}$} \\
\hline$\% \mathrm{PV}(\% B W)$ & $1,42^{\mathrm{A}}$ & $1,29^{\mathrm{A}}$ & $1,06^{\mathrm{AB}}$ & $0,82^{\mathrm{B}}$ & 14,73 & 0,41 \\
\hline $\mathrm{g} / \mathrm{kg}^{0,75}$ & $57,69^{\mathrm{A}}$ & $52,16^{\mathrm{A}}$ & $43,17^{\mathrm{AB}}$ & $33,33^{\mathrm{B}}$ & 14,51 & 16,55 \\
\hline
\end{tabular}

Valores seguidos de mesma letra não diferem entre si $(P>0,05)$ pelo teste de Tukey.

$\mathrm{SMi}$ - Silagem de milho + farelo de soja (Dieta basal).

SRpPc - Dieta basal $(59,13 \%)+$ Silagem de raspa de mandioca com polpa cítrica e uréia.

SCCPC - Dieta basal $(59,17 \%)$ + Silagem de casca de mandioca com polpa cítrica e uréia.

$\mathrm{SCnPc}$ - Silagem de cana-de-açúcar com polpa citrica e uréia.

$\% \mathrm{PV}-\%$ do peso vivo.

CV - Coeficiente de variação; DMS - Diferença mínima significativa.

Values followed by same letters do not differ $(P>.05)$ by Tukey test.

CS - Corn silage + soybean meal (Basal diet).

CrSCp - Basal diet (59.13\%) + Cassava root silage with citrus pulp and urea.

ChSCp - Basal diet (59.17\%) + Cassava hulls silage with citrus pulp and urea.

ScSCp - Sugar cane silage with citrus pulp and urea.

$\% B W-\%$ of body weight.

$\mathrm{CV}$ - coefficient of variation; MSD - minimum significant difference.

digestibilidade, juntamente com a SCnPc (Tabela 4), e que o animal tenta compensar a ingestão de energia aumentando a ingestão de MS, quando não existe outros fatores que limitem o consumo ( $\mathrm{SCnPc})$.

A ingestão de MS da SRpPc, em valores absolutos, foi inferior ao consumo de SMi, apresentando comportamento semelhante ao verificado por outros autores (Caldas Neto et al, 2000; Martins, 1999), podendo estar associado a sua menor palatabilidade, fato não alterado pela inclusão da PCP na silagem. Já o problema de pulverulência relatado por Marques et al. (2000) foi minimizado, em função da forma de apresentação diferente (desidratada ou ensilada, res- pectivamente) e ao maior teor de umidade presente na silagem de raspa.

Para a ingestão de matéria orgânica, o valor observado para a dieta contendo SCcPc $(1,91 \% \mathrm{PV})$ não apresentou diferença $(\mathrm{P}>0,05)$ da SMi e SRpPc, 2,34 e $1,75 \% \mathrm{PV}$, respectivamente, sendo esse intermediário a ambas. Contudo, diferiu $(\mathrm{P}<0,05)$ da $\mathrm{SCnPc}$ $(1,28 \% \mathrm{PV})$ que, por sua vez, foi igual a SRpPc.

Valores de consumo de 2,74; 2,48 e 2,30 \% do PV foram observados por Marques et al. (2000), trabalhando com novilhas alimentadas com dietas à base de silagem de milho e farelo de soja, associados a diferentes fontes energéticas, como milho grão, cas- 
ca e raspa de mandioca desidratada, respectivamente. Esses valores são superiores ao verificado neste estudo, possivelmente em função do balanceamento da dieta utilizado pelos referidos autores, que permitiu ganhos médios diários de 1,7; 1,6 e 1,6 kg, respectivamente, para as três dietas. Entretanto, Martins (1999) verificou consumo de MO de 1,84 \% do PV, para novilhas alimentadas com silagem de milho adicionada de casca de mandioca e levedura, com valor inferior ao observado neste experimento. A ingestão de matéria orgânica da $\operatorname{SCnPc}(51,52 \mathrm{~g} / \mathrm{kg}$ $\left.\mathrm{PV}^{0,75}\right)$ foi superior à verificada por Oliveira (1990) e citada por Rodriguez (1995), com valor médio de $42,93 \mathrm{~g} / \mathrm{kg} \mathrm{PV}^{0,75}$, possivelmente em função da presença de PCP nessa dieta.

A ingestão de proteína bruta (IPB), para todas as dietas, segue o mesmo padrão da ingestão de matéria seca (IMS), uma vez que os teores de PB são próximos, variando de 13,63 a $14,73 \%$, respectivamente, para SMi e SRpPc (Tabela 2). Marques et al. (2000), testando fontes de energia de alta e baixa degradação, para IPB observaram valores de 0,32 ; 0,27 e $0,33 \% \mathrm{PV}$, respectivamente, para a dieta contendo casca de mandioca com milho, raspa de mandioca e milho moído, tendo silagem de milho como volumoso e farelo de soja como fonte protéica. Neste experimento, observaram-se valores de $0,30 \%$; $0,27 \%$ e $0,33 \% \mathrm{PV}$, para os tratamentos contendo SCcPc, SRpPc e SMi.

Caldas Neto et al. (2000), ao estudarem o consumo de $\mathrm{PB}$ por novilhos alimentados com dietas à base de silagem de milho adicionadas com casca e raspa de mandioca desidratada, com aproximadamente $14,0 \%$ de $\mathrm{PB}$, verificaram valor de $0,2 \% \mathrm{PV}$, inferior aos observados neste experimento, que foram de $0,33 \% ; 0,30 \% ; 0,27 \%$ e $0,19 \% \mathrm{PV}$, respectivamente para SMi, SCcPc, SRpPc e SCnPc. Vale salientar que os referidos autores trabalharam com consumo de MS restrito a $2 \% \mathrm{PV}$.

A ingestão de FDN (IFDN), verificada para a $\mathrm{SCcPc}(1,00 \% \mathrm{PV})$, foi semelhante $(\mathrm{P}>0,05)$ a SMi, $\mathrm{SRpPc}$ e SCnPc, $1,14 \% ; 0,73 \%$ e $0,71 \% \mathrm{PV}$, respectivamente. Entretanto as duas últimas foram inferiores a SMi $(\mathrm{P}<0,05)$. Essa menor IFDN para SRpPc está relacionada à menor ingestão de MS (valores absolutos) e ao baixo teor de FDN nessa dieta (38,11 \% MS). A SCnPc, apesar do elevado teor de FDN (53,51 \% da MS), apresentou baixa IFDN, em função da menor IMS $(\mathrm{P}<0,05)$, em relação à SMi e SCcPc.

Martins (1999) verificou valores de 0,85\% e
$1,15 \% \mathrm{PV}$ para dietas contendo silagem de milho associadas com casca de mandioca, em função da fonte protéica, levedura ou farelo de algodão, respectivamente, estando o valor de 1,00\% \%V (SCcPc) intermediário a esses. Da mesma forma, Marques et al. (2000) verificaram valores de 0,$87 ; 0,98$ e $0,76 \%$ PV para milho, casca e raspa de mandioca, respectivamente; somente para silagem de milho verificaram-se divergências nos valores, que se justificam uma vez que os teores de FDN nas dietas foram 31,8 e $46,48 \%$ da MS , respectivamente para os autores.

O consumo de NDT (CNDT) verificado para os animais que recebiam o tratamento com a SCnPc $(0,82$ $\% \mathrm{PV})$ foi inferior $(\mathrm{P}<0,05)$ ao da SMi e SRpPc $(1,42$ e $1,29 \% \mathrm{PV}$, respectivamente). Contudo estas não diferiram da SCcPc $(1,06 \% \mathrm{PV})$, que foi semelhante $(\mathrm{P}>0,05)$ a de SCnPc. Apesar do teor de NDT da silagem de SMi $(57,73 \%)$ ser inferior ao da $\mathrm{SCnPc}(59,83 \%)$, pode-se atribuir o menor $\mathrm{CNDT}(\mathrm{P}<0,05)$ à diferença entre a ingestão de MS, para ambas as dietas.

Cardoso et al. (2000) verificaram CNDT de $1,1 \% \mathrm{PV}$ e $46,68 \mathrm{~g} / \mathrm{kg} \mathrm{PV} \mathrm{PV}^{0,75}$, para bovinos alimentados com dietas apresentando relação volumoso:concentrado de 50\%. Burger et al. (2000) observaram valores de $1,68 \% \mathrm{PV}$ e $59,90 \mathrm{~g} / \mathrm{kg} \mathrm{PV}^{0,75}$ para CNDT, utilizando bezerros holandeses e relação volumoso:concentrado de 40:60. A média dos valores observados para CNDT das SMi, SRpPc e SCcPc, que não apresentaram diferença $(\mathrm{P}>0,05)$, foi de 1,26 $\% \mathrm{PV}$ e $51,00 \mathrm{~g} / \mathrm{kg} \mathrm{PV}^{0,75}$, com valores intermediários aos obtidos pelos referidos autores.

Para o CDA (Tabela 4) da MS e da MO, as dietas $\mathrm{SMi}$ e $\mathrm{SCnPc}$ não apresentaram diferenças entre si $(\mathrm{P}>0,05)$, sendo inferiores a $\mathrm{SRpPc}(\mathrm{P}<0,05)$. Já o valor observado para CDA da SCcPc, 46,53 e 49,14 $\%$, para MS e $\mathrm{MO}$, respectivamente, foi inferior $(\mathrm{P}<0,05)$ a SRpPc $(65,08$ e $66,01 \%)$ e SMi $(56,40$ e $58,07 \%)$, contudo, semelhante $(53,49$ e $54,55 \%)$ a $\mathrm{SCnPc}(\mathrm{P}>0,05)$.

Caldas Neto et al. (2000) verificaram valores de 70,2 e 73,$9 ; 62,8$ e 65,$2 ; 64,6$ e $67,7 \%$, respectivamente, para CDA da MS e MO, utilizando dietas a base de $45 \%$ silagem de milho e como fonte energética a raspa de mandioca, o milho com casca de mandioca e milho, fornecidas a novilhos em consumo restrito. Todavia, Andrade et al. (1994) verificaram CDA da MS de $65,20 \%$ para dietas contendo $30 \%$ de raspa de mandioca ensilada, fornecida a bovinos juntamente com feno de Coastcross, levedura e uréia, corroborando o valor obtido no presente experimento $(65,08 \%)$.

R. Bras. Zootec., v.31, n.3, p.1531-1542, 2002 (suplemento) 
Tabela 4 - Coeficientes de digestibilidade aparente total da matéria seca (DMS), da matéria orgânica (DMO), da energia bruta (DEB), da proteína bruta (DPB) e da fibra detergente neutro (DFDN).

Table 4 - Coefficient total apparent digestibility of dry matter (DMD), of organic matter (OMD), of gross energy (GED), crude protein (CPD) and of neutral detergent fiber (NDFD)

\begin{tabular}{|c|c|c|c|c|c|c|}
\hline \multirow[b]{2}{*}{$\begin{array}{l}\text { Digestibilidade } \\
\text { Digestibility }\end{array}$} & \multicolumn{4}{|c|}{$\begin{array}{l}\text { Silagens } \\
\text { Silages }\end{array}$} & \multirow[b]{2}{*}{$\mathrm{CV}$} & \multirow[b]{2}{*}{$\begin{array}{l}\text { DMS } \\
M S D\end{array}$} \\
\hline & $\begin{array}{l}\text { SMi } \\
C S\end{array}$ & $\begin{array}{l}\text { SRpPc } \\
C r S C p\end{array}$ & $\begin{array}{l}\mathrm{SCcPc} \\
C h S C p\end{array}$ & $\begin{array}{l}\mathrm{SCnPc} \\
S c S C p\end{array}$ & & \\
\hline $\begin{array}{l}\mathrm{DMS} \\
D M D\end{array}$ & $56,40^{\mathrm{B}}$ & $65,08^{\mathrm{A}}$ & $46,53^{C}$ & $53,49^{\mathrm{BC}}$ & 5,59 & 7,58 \\
\hline $\begin{array}{l}\text { DMO } \\
O M D\end{array}$ & $58,07^{\mathrm{B}}$ & $66,91^{\mathrm{A}}$ & $49,14^{\mathrm{C}}$ & $54,55^{\mathrm{BC}}$ & 6,23 & 8,72 \\
\hline $\begin{array}{l}\mathrm{DEB} \\
G E D\end{array}$ & $56,40^{\mathrm{B}}$ & $64,34^{\mathrm{A}}$ & $44,99^{\mathrm{C}}$ & $50,26^{\mathrm{BC}}$ & 5,48 & 7,24 \\
\hline $\begin{array}{l}\text { DPB } \\
C P D\end{array}$ & $58,18^{\mathrm{BC}}$ & $63,26^{\mathrm{AB}}$ & $55,04^{\mathrm{C}}$ & $66,88^{\mathrm{A}}$ & 5,36 & 7,99 \\
\hline $\begin{array}{l}\text { DFDN } \\
N D F D\end{array}$ & $35,07^{\mathrm{A}} \mathrm{B}$ & $39,34^{\mathrm{A}}$ & $15,90^{\mathrm{B}}$ & $36,28^{\mathrm{A}}$ & 25,59 & 19,82 \\
\hline
\end{tabular}

Valores seguidos de mesma letra não diferem entre si $(P>0,05)$ pelo teste de Tukey.

$\mathrm{SMi}-$ Silagem de milho + farelo de soja (Dieta basal).

SRpPc - Dieta basal $(59,13 \%)+$ Silagem de raspa de mandioca com polpa cítrica e uréia.

SCcPc - Dieta basal $(59,17 \%)+$ Silagem de casca de mandioca com polpa cítrica e uréia.

$\mathrm{SCnPc}$ - Silagem de cana-de-açúcar com polpa citrica e uréia.

$\% \mathrm{PV}-\%$ do peso vivo.

CV - Coeficiente de variação; DMS - Diferença mínima significativa.

Values followed by same letters do not differ $(P>.05)$ by Tukey test.

CS - Corn silage + soybean meal (Basal diet).

CrSCp - Basal diet (59.13\%) + Cassava root silage with citrus pulp and urea

ChSCp - Basal diet (59.17\%) + Cassava hulls silage with citrus pulp and urea.

ScSCp - Sugar cane silage with citrus pulp and urea.

$\% B W-\%$ of body weight.

$\mathrm{CV}$ - coefficient of variation; MSD - minimum significant difference.

Martins (1999), trabalhando com novilhas confinadas e alimentadas com dietas a base de silagem de milho, combinada com fontes de energia e proteína apresentando diferentes degradações, observou CDA da MS e MO de 66,2 e 69,4; 60,9 e 63,8 \%, para dietas com casca de mandioca associada a levedura e farelo de algodão, respectivamente. Marques et al. (2000) encontraram CDA da MS e MO de 53,7 e 55,3; 63,1 e 65,$5 ; 73,2$ e $76,8 \%$, respectivamente, para as dietas contendo milho, casca e raspa de mandioca, como fonte energética e silagem de milho como volumoso.

Os valores do CDA da MS e da MO determinados neste experimento são inferiores aos verificados pelos referidos autores, especialmente em relação a SCcPc, que apresentou valores de 46,53 e 49,14\%, para CDA da MS e MO. Tal fato pode estar relacionado ao maior teor de FDN desta dieta $(47,3 \%)$, quando comparado com 38,6\% (Marques et al., 2000). Além disto, por se tratar de resíduos industriais, estes apresentam grande variação na sua composição, o que aliado a forma de apresentação do mesmo (desidratado ou ensilado) pode levar a diferenças no CDA, dificultando a comparação dos dados.

O CDA da MS e da MO da SRpPc (65,08 e
$66,91 \%)$ foi superior as demais dietas $(\mathrm{P}<0,05)$, concordando com os dados relatados por diversos autores (Martins, 1999; Marques et al., 2000, Caldas Neto et al., 2000). Esta superioridade pode ser atribuída a maior quantidade de amido $(20,57 \%)$ presente nesta dieta (Silveira, 2001), maior degradabilidade ruminal do amido da mandioca (Caldas Neto et al., 2000), menor conteúdo de carboidratos estruturais (Tabela 2) e ao menor consumo.

O CDA da PB (Tabela 4) observado para a SCnPc $(66,88 \%)$ foi superior $(\mathrm{P}<0,05)$ ao da $\mathrm{SCcPc}$ e $\mathrm{SMi}$ (55,04 e 58,18\%, respectivamente), não diferindo da $\mathrm{SRpPc}(63,26 \%)$. Esta superioridade da SCnPc esta relacionada ao tipo de proteína presente na dieta, sendo que $42,09 \%$ da PB é proveniente da cana-deaçúcar com PCP, o restante é NNP $(57,91 \%)$ oriundo da uréia, que representa $3,08 \%$ da MS desta dieta.

Fregadolli et al. (2001) avaliando dietas contendo casca de mandioca associada a farelo de algodão e levedura, observaram valores para CDA da PB de 56,1 e $52,2 \%$, respectivamente, sendo próximo ao verificado no presente estudo. Contrariamente, Caldas Neto et al. (2000) verificaram valores de 63,4 e 69,7\% para dietas contendo casca e raspa de mandioca, fornecidas a 
novilhos com consumo restrito a $2 \% \mathrm{PV}$. Estes valores foram superiores ao observado neste estudo, especialmente para SCcPc $(55,04 \%)$, contudo, para SRpPc, a diferença é menor $(63,26 \%)$, e possivelmente tenha ocorrido em função do nível de consumo.

A SMi apresentou CDAPB $(58,18 \%)$ semelhante $(\mathrm{P}>0,05)$ ao da SRpPc e SCcPc, contudo inferior ao verificado por Caldas Neto et al. (2000) e Marques et al. (2000) que foi de 66,8 e 69,9\%, respectivamente. As dietas usadas por ambos autores eram compostas por silagem de milho, milho moído e farelo de soja, com percentuais de 46,0, 42,0 e 12,0\% aproximadamente, enquanto neste estudo o milho não participou.

Os valores médios referentes aos coeficientes de digestão dos nutrientes, conforme o local do trato digestório, em $\%$ do ingerido, $\%$ do digerido e $\%$ do que chega ao duodeno são apresentados na Tabela 5.

A digestibilidade ruminal e pós-ruminal da MS, MO, PB e EB não apresentaram diferenças significativas $(\mathrm{P}>0,05)$ entre as dietas, somente houve diferença $(\mathrm{P}<0,05)$ para a digestão ruminal da FDN, expressa em \% do ingerido, para a $\mathrm{SCcPc}$ com valor de 20,07\%, enquanto para SMi, SRpPc e SCnPc, que não diferiram entre si $(\mathrm{P}>0,05)$ o coeficiente médio foi de $39,93 \%$.

Fregadolli et al. (2001) verificaram valor médio de $26,0 \%$ para a digestão ruminal da FDN, utilizando dietas a base de silagem de milho, milho e casca de mandioca como fonte energética, com consumo restrito, acarretando ingestão de FDN inferior, quando comparado ao presente estudo $(0,79$ contra $1,00 \% \mathrm{PV})$.

Os animais que receberam o tratamento com a $\mathrm{SCcPc}$ sistematicamente mostraram-se inferiores aos demais, para os parâmetros avaliados, contrastando com os dados verificados na literatura. Este comportamento parece estar associado a contaminação deste resíduo com terra, fato perceptível visualmente quando da ensilagem do resíduo e que veio se confirmar através do elevado teor de matéria mineral $(13,92 \%$ MS), enquanto as outras silagens apresentaram valor médio de 5,39 \% MS. Esta contaminação possivelmente ocorreu em função do nível tecnológico da indústria.

Outro fator que pode explicar estes resultados é que entre as silagens avaliadas, a de SCcPc possuía o menor nível de inclusão de PCP, que poderia melhorar os valores observados nos parâmetros avaliados, devido suas características. Também pode ter efeito negativo sobre a digestibilidade da fibra a contaminação do alimento com terra ( $\mathrm{SCcPc}$ ), especialmente quando os valores de FDN e FDA não são corrigidos para cinza, conforme verificaram Crocker et al. (1998). Os autores concluíram que em todos os casos a digestibilidade com a FDN e FDA corrigidas para cinza foram maiores que as estimadas com FDN e FDA não corrigido.

O coeficiente de digestão ruminal (CDR) da MS observado neste experimento foi superior ao verificado por Caldas Neto et al. (2000), com valor médio de 70,4 e $66,0 \%$, respectivamente. Já para o CDR da MO foram encontrados 72,3 e 74,1\% (em relação ao digerido), respectivamente, para ambos experimentos. Estes valores são corroborados por Rodriguez (1995) ao relatar que em alimentos apresentando fonte de carboidratos não estrutural (CNE), a participação do rúmen na digestão pode variar entre $60 \mathrm{a}$ $85 \%$ da MO aparentemente digerida.

Os resíduos da mandioca são fonte de CNE, além da PCP que apresenta em sua composição grande quantidade de pectina com disponibilidade nutricional completa para ruminantes (Van Soest, 1994) e apresenta degradabilidade potencial com $48 \mathrm{~h}$ (Porcionato et al., 2000), e coeficientes de digestibilidade aparente da MS, FDN e FDA de 84,14, 67,72 e 86,00 \%, respectivamente (Bruno Filho et al., 2000).

Berchielli (1994) estudou os efeitos de níveis crescentes de concentrado na dieta de novilhos (20, 40 e $60 \%$ ) e verificou valores médios de 80,24 e $85,48 \%$ para digestibilidade ruminal da MS e MO, respectivamente. Da mesma forma, Cardoso et al. (2000) estudaram níveis crescentes de concentrado na dieta de novilhos e observaram valores médios de 54,45 e $64,67 \%$ para CDR da MS e MO, respectivamente. Os valores verificados no presente estudo para CDR da MS e MO (70,40 e 72,33\%) são intermediários aos verificados por estes autores.

O CDA total da silagem de raspa e de casca de mandioca com PCP, obtida pelo método indireto, com o auxílio da dieta basal (Lucci, 1997), apresentou os seguintes valores: $81,69,77,82,71,20$ e $79,89 \%$ e 34,18 , $37,28,34,52$ e $23,43 \%$, respectivamente, para silagem de raspa e casca de mandioca, amostradas nos quatro períodos experimentais. Pelos dados apresentados, merece destaque a acentuada queda no CDA da MS verificada para a silagem de raspa, após a abertura do silo, denotando sua rápida deterioração (períodos de 1 a 3), já que no quarto período foi aberto novo silo. Outro ponto refere-se à baixa digestibilidade da silagem de casca de mandioca, que teve $36,3 \%$ da sua MS constituída por PCP, que sozinha apresenta CDA da MS de 84,14 \% (Bruno Filho et al., 2000 ).

R. Bras. Zootec., v.31, n.3, p.1531-1542, 2002 (suplemento) 
Tabela 5 - Digestão ruminal e intestinal da matéria seca(MS), da matéria orgânica(MO), da proteína Bruta(PB), da energia bruta(EB) e da fibra detergente neutro(FDN)

Table 5 - Ruminal and intestinal digestion of dry matter (DM), organic matter (OM), crude protein (CP), gross energy (GE), neutral detergent fiber (NDF)

\begin{tabular}{|c|c|c|c|c|c|c|}
\hline \multirow{3}{*}{$\begin{array}{l}\text { Parâmetro } \\
\text { Parameter }\end{array}$} & \multicolumn{4}{|c|}{$\begin{array}{c}\text { Dietas } \\
\text { Diets }\end{array}$} & \multirow{3}{*}{$\mathrm{CV}$} & \multirow{3}{*}{$\begin{array}{l}\text { DMS } \\
M S D\end{array}$} \\
\hline & SMi & SRpPc & $\mathrm{SCcPc}$ & $\mathrm{SCnPc}$ & & \\
\hline & $C S$ & $\mathrm{CrSCp}$ & $C h S C p$ & $S c S C p$ & & \\
\hline \multicolumn{7}{|c|}{$\begin{array}{l}\text { Digestão ruminal \% } \\
\text { Ruminal digestion \% }\end{array}$} \\
\hline$M^{1}{ }^{1}(D M)$ & 39,27 & 45,96 & 34,51 & 35,86 & 14,88 & 14,17 \\
\hline$M^{2}(D M)$ & 69,73 & 70,66 & 73,83 & 67,39 & 15,37 & 26,49 \\
\hline $\mathrm{MO}^{1}(O M)$ & 41,61 & 48,80 & 37,54 & 37,38 & 12,24 & 12,38 \\
\hline $\mathrm{MO}^{2}(O M)$ & 71,75 & 73,00 & 75,77 & 68,80 & 13,09 & 23,1 \\
\hline $\mathrm{PB}^{1}(\mathrm{CP})$ & 1,83 & 29,84 & 22,46 & 20,61 & 116,43 & 53,25 \\
\hline $\mathrm{PB}^{2}(C P)$ & 2,29 & 47,30 & 40,86 & 30,62 & 121,07 & 89,70 \\
\hline $\operatorname{EB}^{1}(G E)$ & 46,63 & 47,41 & 42,78 & 39,47 & 16,13 & 17,41 \\
\hline $\operatorname{EB}^{2}(G E)$ & 82,78 & 73,84 & 94,71 & 79,03 & 18,18 & 36,76 \\
\hline $\mathrm{FDN}^{1}(N D F)$ & $43,47^{\mathrm{A}}$ & $39,26^{\mathrm{A}}$ & $20,07 \mathrm{~B}$ & $37,08^{A}$ & 13,47 & 11,53 \\
\hline $\mathrm{FDN}^{2}(N D F)$ & 124,91 & 100,15 & 135,86 & 113,68 & 32,28 & 93,78 \\
\hline \multicolumn{7}{|c|}{$\begin{array}{c}\text { Digestão intestinal \% } \\
\text { Intestinal digestion \% }\end{array}$} \\
\hline $\mathrm{MS}^{1}(D M)$ & 17,12 & 19,12 & 12,01 & 17,63 & 35,40 & 14,27 \\
\hline $\mathrm{MS}^{2}(D M)$ & 30,27 & 29,34 & 26,17 & 32,60 & 36,56 & 26,49 \\
\hline $\mathrm{MS}^{3}(D M)$ & 27,68 & 34,08 & 16,86 & 26,92 & 28,15 & 18,18 \\
\hline $\mathrm{MO}^{1}(O M)$ & 16,45 & 18,10 & 11,60 & 17,17 & 33,90 & 13,14 \\
\hline $\mathrm{MO}^{2}(O M)$ & 28,24 & 26,99 & 24,23 & 31,19 & 34,24 & 23,19 \\
\hline $\mathrm{MO}^{3}(O M)$ & 27,68 & 34,08 & 16,86 & 26,92 & 28,15 & 18,18 \\
\hline $\mathrm{PB}^{1}(C P)$ & 56,35 & 33,43 & 32,58 & 46,27 & 47,42 & 48,94 \\
\hline $\mathrm{PB}^{2}(C P)$ & 97,72 & 52,70 & 59,14 & 69,38 & 52,55 & 89,70 \\
\hline $\mathrm{PB}^{3}(C P)$ & 55,65 & 40,61 & 33,61 & 57,26 & 33,95 & 38,87 \\
\hline $\operatorname{EB}^{1}(G E)$ & 9,76 & 16,92 & 2,20 & 10,78 & 69,90 & 16,97 \\
\hline $\mathrm{EB}^{2}(G E)$ & 17,23 & 26,16 & 5,29 & 20,97 & 86,25 & 36,76 \\
\hline $\mathrm{EB}^{3}(G E)$ & $16,93^{\mathrm{AB}}$ & $29,16^{\mathrm{A}}$ & $-3,90^{\mathrm{B}}$ & $17,58^{\mathrm{AB}}$ & 83,11 & 30,40 \\
\hline $\mathrm{FDN}^{1}(N D F)$ & $-8,40$ & 0,075 & $-4,16$ & $-0,79$ & $-173,51$ & 14,11 \\
\hline $\mathrm{FDN}^{2}(N D F)$ & $-24,91$ & $-0,15$ & $-35,86$ & $-13,68$ & $-205,41$ & 93,78 \\
\hline $\mathrm{FDN}^{3}(N D F)$ & $-15,86$ & $-1,79$ & $-5,51$ & $-0,68$ & $-154,79$ & 22,59 \\
\hline
\end{tabular}

$1=\%$ do ingerido; $2=\%$ do total digestível e $3=\%$ do que chegou ao duodeno.

Médias seguidas de letras diferentes, são diferentes $(P<0,05)$ pelo teste de Tukey.

$\mathrm{SMi}$ - Silagem de milho + farelo de soja (Dieta basal).

SRpPc - Dieta basal $(59,13 \%)$ + Silagem de raspa de mandioca com polpa cítrica e uréia

SCCPC - Dieta basal $(59,17 \%)+$ Silagem de casca de mandioca com polpa cítrica e uréia.

$\mathrm{SCnPc}$ - Silagem de cana-de-açúcar com polpa cítrica e uréia.

CV - Coeficiente de variação; DMS - Diferença mínima significativa.

$1=\%$ intake; $2=\%$ of the total digestible and $3=\%$ of the amount that reached the duodenum.

Average followed letters different, are different $(P<0.05)$ by Tukey test.

CS - Corn silage + soybean meal (Basal diet).

CrSCp - Basal diet (59.13\%) + Cassava root silage with citrus pulp and urea.

ChSCp - Basal diet (59.17\%) + Cassava hulls silage with citrus pulp and urea.

ScSCp - Sugar cane silage with citrus pulp and urea.

$C V$ - coefficient of variation; MSD - minimum significant difference.

As dietas apresentaram valores médios para CDR de $70,4,72,33,30,26,118,65 \%$ e para CDI de 29,60, $27,67,69,74,-18,65 \%$, respectivamente, para a MS, MO, PB, e FDN, quando expressos em \% do total digerido. Berchielli (1994) verificou valores de 76,81, $81,08,92,69 \%$ e $23,19,18,92$ e $7,31 \%$ para os CDR e CDI da MS, MO, e FDN, respectivamente, em estudo com bovinos alimentados com feno de coastcross e concentrado, na proporção de 40:60. Os valores para o CDR referentes a FDN foram superiores aos verificados por Berchielli (1994), contudo aproximaram-se do valor médio verificado por Tibo et al. (2000), de 104,42\%, estudando níveis crescentes de concentrado na dieta. Da mesma

\footnotetext{
R. Bras. Zootec., v.31, n.3, p.1531-1542, 2002 (suplemento)
} 
forma, Carvalho et al. (1997) encontraram valores variando entre 104,94 e 92,07, em função dos níveis de concentrado. Valores superiores a $100 \%$ podem estar relacionados a superestimava do fluxo duodenal de MS, fato também relatado por Cardoso et al. (2000).

Valores negativos para o CDI da FDN são relativamente comuns (Carvalho et al., 1997; Cardoso et al., 2000; Fregadolli et al., 2001 e Tibo et al. 2000), estando, em geral, associados a problemas com o indicador utilizado para estimativa do fluxo duodenal de MS (Rodriguez, 1995), que por sua vez irá apresentar reflexos na partição da digestão de todos os nutrientes (Berchielli et al., 1998).

A média do CDR para PB obtidos neste estudo (\% do ingerido), foi de 18,68, concordando com o verificado por Carvalho et al., (1997), que não encontraram diferenças entre níveis crescente de concentrado, com valor de 18,02\%. Todavia, contrastam com Caldas Neto et al. (2000) que obtiveram valores de $6,7,8,6,6,8$ e $4,3 \%$, para dietas contendo milho, milho com casca de mandioca, raspa de mandioca e farinha de varredura, respectivamente. A presença de uréia nas dietas experimentais, neste estudo, pode ter sido responsável pelo maior CDR da $\mathrm{PB}$ verificado, uma vez que sua degradação ruminal é total.

Os elevados valores verificados para o coeficiente de variação $(\mathrm{CV})$ referente ao CDR da PB $(116,43$ e 121,07 \%) estão relacionados com a transformação da proteína dietética em proteína microbiana, podendo inclusive apresentar valores negativos, como os verificados por Fregadolli et al. (2001), com média de $-18,5 \%$ para o CDR da PB e $-82,22 \%$ para o CV.

Para o CDI da PB, \% do que chegou ao duodeno, os valores obtidos por Caldas Neto et al. (2000) e Fregadolli et al. (2001) foram superiores $(63,8 \mathrm{e}$ $60,77 \%$, respectivamente) ao verificado neste estudo (46,78\%), possivelmente pelo maior percentual de proteína verdadeira presente nas dietas utilizadas por ambos autores. Já neste experimento o nitrogênio não protéico, na forma de uréia, representou, em média, $29,34 \%$ da PB das dietas (MS).

A ingestão, o coeficiente de digestibilidade aparente (CDA), a digestão ruminal e intestinal, assim como, os valores energéticos das dietas experimentais estão apresentados na Tabela 6 .

A ingestão de energia bruta (IEB) foi superior $(\mathrm{P}<0,05)$ para $\mathrm{SMi}$, em relação a $\mathrm{SCnPc}$ e SRpPc que não diferiram entre si, observando-se valores de $428,19,232,30$ e $308,69 \mathrm{kcal} / \mathrm{kg} \mathrm{PV}^{0,75}$, respectiva- mente. A SCcPc não diferiu da SMi e da SRpPc apresentando valor intermediário de $350,50 \mathrm{kcal} / \mathrm{kg}$ $\mathrm{PV}^{0,75}$. O CDA da EB para SRpPc foi superior $(\mathrm{P}<0,05)$ aos demais $(64,34 \%)$, sendo que entre SMi e $\mathrm{SCnPc}$ não houve diferença. Fregadolli et al. (2001) verificaram CDA de 56,8, e 60,5\%, para novilhos alimentados com silagem de milho, associada ao milho e a casca de mandioca desidratada, como fonte energética, suplementados com farelo de algodão. Para SMi os valores estão próximos (56,4 e 56,8\%), divergindo porém, para o tratamento utilizando a casca de mandioca, que foi superior $(44,99$ e $60,5 \%$, para este estudo e Fregadolli et al. (2001), respectivamente.

Para digestão ruminal (DR) e digestão intestinal (DI) da EB, não foram verificadas diferenças $(\mathrm{P}>0,05)$ entre as dietas, apresentando valor médio de $82,59 \mathrm{e}$ $17,41 \%$, respectivamente. Berchielli (1994) verificou DR e DI da EB de 83,8 e 16,20\%, respectivamente, utilizando dietas a base de feno de coastcross e concentrado (60:40). Este autor relata também a semelhança entre digestibilidade ruminal da energia e da MO, fato não foi verificado neste estudo, já que a MO apresentou em média 72,33 e 27,67\%, para DR e DI, respectivamente.

Caldas Neto et al. (2000) que também não encontraram diferenças entre as dietas para DR e DI da EB ( $\%$ do total digerido), obteve valores médios de 71,55 e $28,45 \%$, respectivamente. Estes valores foram inferior e superior ao observado neste estudo (Tabela 6).

O conteúdo de NDT calculado (Sniffen et al., 1992) variou entre as dietas, sendo de $68,35 \%$ para $\mathrm{SRpPc}$, que não diferiu $(\mathrm{P}>0,05)$ da $\operatorname{SCnPc}(59,83 \%)$ e foi superior aos demais tratamentos. Tal fato devese ao maior conteúdo de carboidratos não estruturais presentes neste tratamento ( $\mathrm{SRpPc}-42,44 \%$ ) em relação a média dos outros três $(31,38 \%)$, que associado ao menor consumo de MS verificado para ambas dietas (Tabela 3 ) afeta positivamente o CDA e conseqüentemente o conteúdo de NDT. Para a SMi o valor observado $(57,73 \%)$ foi igual a $\mathrm{SCnPc}(59,63$ $\%)$ e a $\mathrm{SCcPc}(50,04 \%)$, que apresentou o menor valor entre as dietas. Este comportamento foi semelhante ao verificado para o CDA da MS, MO e EB das dietas (Tabela 4).

Houve diferença entre as dietas para ED, energia metabolizável (EM), energia líquida de mantença (Elm) e energia líquida de ganho (Elg), sendo que a SMi e a SRpPc foram semelhantes $(\mathrm{P}>0,05)$, assim como a $\mathrm{SCnPc}$ e a $\mathrm{SCcPc}$, contudo, as duas primeiras diferiram das duas últimas $(\mathrm{P}<0,05)$. 
Tabela 6 - Ingestão (IEB), digestibilidade total e parcial da energia bruta e valores energéticos das dietas experimentais Table 6 - Gross energy intake (GEI), apparent digestibility coefficient and partial digestion of gross energy values of the experimental diets

\begin{tabular}{|c|c|c|c|c|c|c|}
\hline \multirow{3}{*}{$\begin{array}{l}\text { Parâmetro } \\
\text { Parameter }\end{array}$} & \multicolumn{4}{|c|}{$\begin{array}{l}\text { Tratamentos } \\
\text { Treatments }\end{array}$} & \multirow{3}{*}{$\mathrm{CV}$} & \multirow{3}{*}{$\begin{array}{l}\text { DMS } \\
M S D\end{array}$} \\
\hline & SMi & $\mathrm{SRpPc}$ & $\mathrm{SCcPc}$ & $\mathrm{SCnPc}$ & & \\
\hline & $C S$ & $\stackrel{C r S C p}{ }$ & $C h S C p$ & $S c S C p$ & & \\
\hline IEB (GEI) kcal $/ \mathrm{kg}^{0,75}$ & $428,19^{\mathrm{a}}$ & $308,69 \mathrm{bc}$ & $350,50^{\mathrm{ab}}$ & $232,30^{\mathrm{c}}$ & 11,43 & 92,34 \\
\hline $\mathrm{CDA}_{\mathrm{EB}}\left(A D C_{G E}\right) \%$ & $56,40^{\mathrm{b}}$ & $64,34^{\mathrm{a}}$ & $44,99^{\mathrm{c}}$ & $50,26^{\mathrm{bc}}$ & 5,48 & 7,24 \\
\hline $\mathrm{DR}_{\mathrm{EB}}\left(R D_{G E}\right) \% 3$ & 82,78 & 73,84 & 94,71 & 79,03 & 18,18 & 36,76 \\
\hline $\mathrm{DI}_{\mathrm{EB}}\left(I D_{G E}\right) \% 3$ & 17,23 & 26,16 & 5,29 & 20,97 & 86,25 & 36,76 \\
\hline $\mathrm{NDT}^{2}(T D N) \%$ & $57,73^{b c}$ & $68,35^{\mathrm{a}}$ & $50,04^{\mathrm{c}}$ & $59,83^{\mathrm{ab}}$ & 5,94 & 8,58 \\
\hline $\mathrm{ED}^{2}(D E) \mathrm{Mcal} / \mathrm{kg}$ & $2,43^{\mathrm{a}}$ & $2,67^{\mathrm{a}}$ & $1,86^{\mathrm{b}}$ & $2,03^{\mathrm{b}}$ & 5,53 & 0,30 \\
\hline $\mathrm{EM}^{2}(M E) \mathrm{Mcal} / \mathrm{kg}$ & $2,00^{\mathrm{a}}$ & $2,19^{\mathrm{a}}$ & $1,53^{\mathrm{b}}$ & $1,66^{\mathrm{b}}$ & 5,56 & 0,25 \\
\hline $\mathrm{Elm}^{2}(N E m) \mathrm{Mcal} / \mathrm{kg}$ & $1,15^{\mathrm{a}}$ & $1,32^{\mathrm{a}}$ & $0,69^{\mathrm{b}}$ & $0,82^{\mathrm{b}}$ & 10,34 & 0,25 \\
\hline $\mathrm{Elg}^{2}$ (NEg) Mcal $/ \mathrm{kg}$ & $0,59^{\mathrm{a}}$ & $0,75^{\mathrm{a}}$ & $0,16^{\mathrm{b}}$ & $0,28^{\mathrm{b}}$ & 21,89 & 0,23 \\
\hline
\end{tabular}

Médias na mesma linha, seguidas de letras diferentes, são diferentes $(P<0,05)$ pelo teste de Tukey.

* CDA: coeficiente de digestibilidade aparente, DR: digestão ruminal e DI: digestão intestinal; NDT: nutrientes digestíveis totais; ED: energia digestível; EM: energia metabolizável, Elm: energia líquida de mantença; Elg: energia líquida de ganho das dietas experimentais.

1 SMi: dieta basal; SRpPc: dieta basal + silagem de raspa de mandioca com polpa cítrica e uréia; SCcPc: dieta basal + silagem de casca de mandioca com polpa cítrica e uréia; SCcPc: silagem de cana com polpa cítrica e uréia.

2 Valores calculados segundo Sniffen et al., $1992 ;{ }^{3}=\%$ do digerido.

CV - coeficiente de variação; DMS - Diferença mínima significativa.

Means in the same row, followed different letters, are different $(P<.05)$ by Tukey test.

* ADC: apparent digestibility coefficient, RD: ruminal digestion and ID: intestinal digestion; TDN: total digestible nutrients, DE: digestible energy, ME: metabolizable energy, NEM: net energy for maintenance, NEG: net energy for body gain.

${ }^{1}$ CS: corn silage (basal diet); CrSCp: basal diet + cassava root silage with citrus pulp and urea; ChSCp: basal diet + cassava hulls silage with citrus pulp and urea; ScSCp: sugar cane silage with citrus pulp and urea.

2 Values calculated by Sniffen et al. (1992); ${ }^{3}=\%$ of digested.

$C V$ - coefficient of variation; MSD - minimum significant difference.

Fregadolli et al. (2001) verificaram ED, EM, Elm e Elg de 2,5, 2,05, 1,2 e $0,65 \mathrm{Mcal} / \mathrm{kg}$, respectivamente, para dieta contendo casca de mandioca, contrastando com os valores verificados $(1,86,1,53,0,69 \mathrm{e} 0,16 \mathrm{Mcal} /$ $\mathrm{kg}$, respectivamente). Da mesma forma, Caldas Neto et al. (2000) observaram valores de 2,8,2,3,1,4, 0,8 e 3,0, $2,5,1,6$ e 1,0, respectivamente, para dietas contendo milho com casca de mandioca e raspa de mandioca. Os valores inferiores verificados podem estar relacionados as características observadas na formulação das dietas para os respectivos experimentos.

\section{Conclusões}

A silagem de raspa de mandioca com polpa cítrica pode ser uma boa alternativa para a suplementação de ruminantes, em função do bom consumo e qualidade apresentada, refletida pelo maior coeficiente de digestibilidade aparente da matéria seca e pelo maior valor de NDT. Contudo, sua rápida deterioração após abertura do silo indica a necessidade de manejo adequado para retirada e fornecimento da silagem aos animais.

A silagem de casca de mandioca com polpa cítrica apresentou qualidade inferior às demais.

\section{Literatura Citada}

AGRICULTURAL AND FOOD RESEARCH COUNCIL - AFRC. Technical committee on responses to nutrients: energy and protein requirements of ruminants. Wallingford: $C A B$ International, 1995. 159p.

ANDRADE, P.; AZEVEDO, A.L.G.; ALCADE, C.R. Digestibilidade da raspa de mandioca (Manhotesculenta) ensilada para ruminantes. In: REUNIÃO ANUAL DA SOCIEDADE BRASILEIRA DE ZOOTECNIA, 31., 1994, Maringá. Anais... Maringá: Sociedade Brasileira de Zootecnia, 1994. p.536.

ASSOCIATION OF OFICIAL ANALYTICAL CHEMISTIS AOAC. Official methods of analysis. 15.ed. Arlington, Virginia. v.2. 1990. 1298p.

BERCHIELLI, T.T. Efeito da relação volumoso:concentrado sobre a partição da digestão, a síntese de proteína microbiana, produção de ácidos graxos voláteis e o desempenho de novilhos em confinamento. Belo Horizonte: Universidade Federal de Minas Gerais, 1994. 104p. Tese (Doutorado em Zootecnia) - Universidade Federal de Minas Gerais, 1994.

BERCHIELLI, T.T.; RODRIGUEZ, N.M.; OSÓRIO NETO, E. et al. Comparação de indicadores de fase sólida para medir fluxo de matéria seca e matéria orgânica no duodeno. Arquivo Brasileiro de Veterinária e Zootecnia, v.50, n.2, p.147-152, 1998.

BERCHIELLI, T.T.; ANDRADE, P.; FURLAN, C.L. Avaliação de indicadores internos em ensaios de digestibilidade. Revista Brasileira de Zootecnia, v.29, n.3, p.830-833, 2000.

BRUNO FILHO, J.R.; BERCHIELLI, T.T.; ANDRADE, P. et al. Digestibilidade da polpa cítrica peletizada na alimentação de

R. Bras. Zootec., v.31, n.3, p.1531-1542, 2002 (suplemento) 
bovinos. In: REUNIÃO ANUAL DA SOCIEDADE BRASILEIRA DE ZOOTECNIA, 37., 2000, Viçosa, MG. Anais... São Paulo: SBZ/Gnosis, [2000]. CD-ROM. Nutrição de Ruminantes. Oral-0806.

BURGER, P.J.; PEREIRA, J.C.; SILVA, J.F.C. et al. Consumo e digestibilidade aparente total e parcial em bezerros holandeses alimentados com dietas contendo diferentes níveis de concentrado. Revista Brasileira de Zootecnia, v.29, n.1, p.206-214, 2000.

BURGI. R. Uso de resíduos agrícolas de agro-industriais na alimentação de bovinos. In SIMPÓSIO SOBRE MANEJO E NUTRIÇÃO DE GADO DE CORTE, 2000, Goiânia. Anais... Goiânia: Colégio Brasileiro de Nutrição Animal, 2000. p.153-162.

CALDAS NETO, S.; ZEOULA, M.L.; PRADO, I.N. et al. Mandioca e resíduos das farinheiras na alimentação de ruminantes: digestibilidade total e parcial. Revista Brasileira de Zootecnia, v.29, n.6, supl. 1, p.2099-2108, 2000.

CARDOSO, R.C.; VALADARES FILHO, S.C.; SILVA, J.F.C. et al. Consumo e digestibilidades aparentes totais e parciais de rações contendo diferentes níveis de concentrado, em novilhos F1 Limousin x Nelore. Revista Brasileira de Zootecnia, v.29, n.6, p.1832-1843, 2000.

CARVALHO, A.U.; VALADARES FILHO, S.C.; SILVA, J.F.C. et al. Níveis de concentrado em dietas de zebuínos. 2. Coeficientes de digestibilidade aparentes parciais. Revista Brasileira de Zootecnia, v.26, n.5, p.996-1006, 1997.

CEREDA, M. P. Valorização de resíduos como forma de reduzir custo de produção. In: CONGRESSO LATINO-AMERICANO DE RAÍZES TROPICAIS, 1., 1996, São Pedro. Anais... São Pedro: 1996. p.25-43.

CROCKER, L.M.; DePETERS, E.J.; FADEL, J.G. et al. Ash content of detergent fibers in feeds, digesta, and feces and its relevance in fiber digestibility calculations. Journal of Dairy Science, v.81, n.3, p.1010-1014, 1998.

FREGADOLLI, F.L.; ZEOULA, M.L.; PRADO, I.N. et al. Efeito das fontes de amido e nitrogênio de diferentes degradabilidades ruminais. 1. Digestibilidade parcial e total. Revista Brasileira de Zootecnia, v.30, n.3, p.858-869, 2001.

HENRIQUE, W.; LEME, P. R.; LANNA, D. P. D. et al. Efeito de diferentes fontes de polpa cítrica peletizada e níveis de concentrado na dieta de novilhas confinadas. In: REUNIÃO ANUAL DA SOCIEDADE BRASILEIRA ZOOTECNIA, 35., 1998, Botucatu. Anais... Botucatu: Sociedade Brasileira de Zootecnia, 1998. p.41.

JERACI, J.L.; HERNANDEZ, T.; ROBERTSON, J.B. et al. New and improved procedure for neutral detergent fiber. Journal Animal Science, v.66, p.351 (Abstracts). 1988. (Suppl. 1)

LUCCI, C.S. Nutrição e manejo de bovinos leiteiros. São Paulo: Manole, 1997. 169p.

MARQUES, J.A.; PRADO, I.N.; ZEOULA, M.L. et al. Avaliação da mandioca e seus resíduos industriais em substituição ao milho no desempenho de novilhas confinadas. Revista Brasileira de Zootecnia, v.29, n.5, p.1529-1535, 2000.
MARTINS, A. S. Efeito de rações diferenciadas pelo ritmo de degradação ruminal sobre o desempenho de novilhas confinadas. Maringá: Universidade Estadual de Maringá, 1999. 81p. Dissertação (Mestrado em Zootecnia) - Universidade Estadual de Maringá, 1999.

PORCIONATO, M.A.F.; BERCHIELLI, T.T.; FRANCO, G.L. et al. Avaliação dos parâmetros ruminais da polpa cítrica peletizada 1 - Degradação da MS e FDN. In: REUNIÃO ANUAL DA SOCIEDADE BRASILEIRA DE ZOOTECNIA, 37., 2000, Viçosa. Anais... São Paulo: SBZ/Gmosis, [2000]. CD-ROM. Nutrição de Ruminantes. Oral-0577.

RIBEIRO, J.M.A. Composição bromatológica da polpa cítrica peletizada reidratada e ensilada. Jaboticabal: Universidade Estadual Paulista. 1998. 27p. Monografia (Graduação em Zootecnia) - Universidade Estadual Paulista, 1998.

RODRIGUEZ, N.M. Pesquisas sobre dinâmica da fermentação ruminal e partição da digestão realizadas no departamento de zootecnia da UFMG. In: SIMPÓSIO INTERNACIONAL SOBRE EXIGÊNCIAS NUTRICIONAIS DE RUMINANTES, 1995, Viçosa, MG. Anais... Viçosa: Universidade Federal de Viçosa, 1995. p.389-417.

SILVEIRA, R.N. Avaliação nutricional de silagens de resíduos de mandioca e cana-de-açúcar, com polpa cítrica, para bovinos. Jaboticabal: Universidade Estadual Paulista, 2001. 57p. Dissertação (Mestrado em Zootecnia) - Universidade Estadual Paulista, 2001.

SNIFFEN, C.J.; O'CONNOR, P.J.; Van SOEST, P.J. et al., A net carbohydrate and protein system for evaluation cattle diets: II. Carbohydrate and protein availability. Journal of Animal Science, v.70, n.3, p.3562-3577, 1992.

SORBARA, J.O.B.; NAKAGE, E.S.; FRANCO, G.L. et al. Utilização da polpa de citrus peletizada como material para cama de frangos de corte-análise bromatológica. In: REUNIÃO ANUAL DA SOCIEDADE BRASILEIRA DEZOOTECNIA, 37., 2000, Viçosa, MG. Anais... São Paulo: SBZ/Gmosis, [2000]. CDROM. Nutrição de Ruminantes. Pôster-0810.

TIBO, G.C.; VALADARES FILHO, S.C.; VALADARES, R.F.D. et al. Níveis de concentrado em dietas de novilhos mestiços F1 Simental x Nelore. 1 Consumo e digestibilidades. Revista Brasileira de Zootecnia, v.29,n.3, p.910-920, 2000.

VALVASORI, E.;ZANETTI, M.A.; MELOTTI, L. et al. Avaliação da silagem de cana-de-açúcar através de ensaio de digestibilidade (aparente) com ovinos. Boletim da Indústria Animal, v.54, n.1, p.75-79, 1997.

Van SOEST, P.J. Nutritional ecology of the ruminant. 2.ed. Cornell: Cornell University Press, 1994. 476p. 